\title{
CM-SCALE AIR TURBINE AND GENERATOR FOR ENERGY HARVESTING FROM LOW-SPEED FLOWS
}

\author{
A. Bansal, D.A. Howey, and A.S. Holmes* \\ Department of Electrical and Electronic Engineering, \\ Imperial College, London SW7 2AZ, UK
}

\begin{abstract}
We have developed a 2-cm-diameter, shrouded wind turbine with an integrated axial flux permanent magnet generator. The device was fabricated using a combination of rapid prototyping, traditional machining and flexible printed circuit board technology, and employs jewel bearings for low friction. Wind tunnel tests have been performed on prototypes with 6 and 12 blades. The 12blade design achieves a generator output power of $4.3 \mathrm{~mW}$ at a tunnel flow speed of $10 \mathrm{~ms}^{-1}$, and will operate at flow speeds down to $4.5 \mathrm{~ms}^{-1}$. With such a low drop-out speed the device could be used as an energy harvester in duct sensing applications.
\end{abstract}

\section{KEYWORDS}

Energy harvesting; air turbine; axial flux generator

\section{INTRODUCTION}

Energy scavenged from ambient gas flow could provide power for wireless sensors in a range of future applications, including air flow/quality control in buildings and remote gas pipeline monitoring. Several research groups have investigated miniature energy scavengers based on turbines in recent years [1-3]. To date these devices have been relatively large, with rotor areas between $14 \mathrm{~cm}^{2}$ and $300 \mathrm{~cm}^{2}$, and constructed from parts originally designed for other applications; no optimization has been carried out. More recently flow-driven vibratory generators have also started to emerge [4].

All miniature flow-driven energy scavengers exhibit low efficiency because of high viscous losses, and with turbines the losses associated with the bearings and clearances also scale unfavourably. We have developed a 2-cm-diameter wind turbine with an integrated electromagnetic generator as a flexible test bed for exploring the performance limits of turbines at this scale.

Figure 1 shows a cross-section of the device, which consists of a shrouded turbine with an axial flux permanent magnet (AFPM) generator built into the shroud. By placing the generator outside the turbine, good matching can be achieved between the power ratings of the two when they are directly coupled. This eliminates the need for a gearbox which would introduce additional losses. We have previously reported a smaller device with a similar turbine geometry [5]. However, in that design the generator was placed at the hub and had limited power generation capability. Also, the MEMS-based construction did not allow easy variation of design parameters.

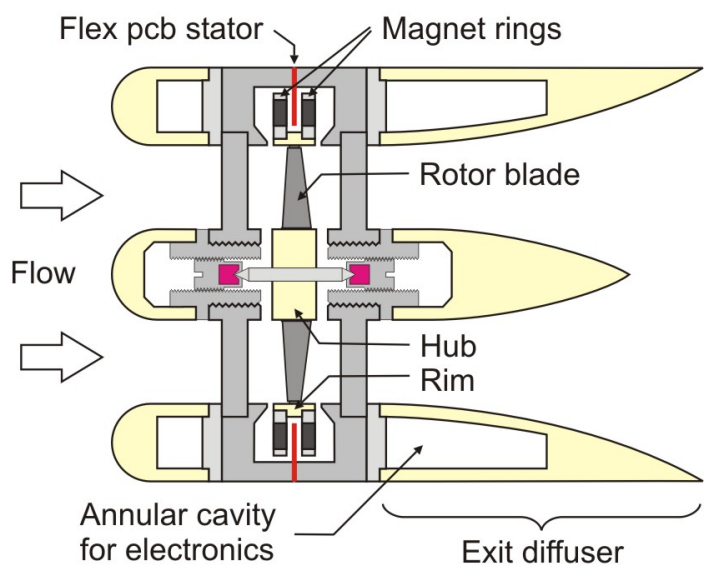

Figure 1: Schematic view of device in cross-section.

\section{TURBINE DESIGN}

Very little published data is available to inform the design of $\mathrm{cm}$-scale air turbines. In such devices the Reynolds number is low (typically $<10,000$ ) and the flow is laminar or transitional. Laminar boundary layers are less stable in the presence of adverse pressure gradients than are turbulent ones, and are prone to leading edge separation giving increased drag [6]. Viscous losses are large and the lift to drag ratio is typically one to two orders of magnitude below that of larger scale airfoils. Consequently $\mathrm{cm}$-scale turbines are expected to offer relatively poor performance, and before the advent of lowpower wireless sensor technology there was no compelling reason to develop them.

We have used a simple two-dimensional blade element momentum (BEM) analysis to produce initial designs. The BEM method is often used in studies of large horizontal axis wind turbines [7]. Standard NACA airfoil shapes were used, with the lift and drag data being derived from previous work on low Reynolds number airfoils for microUAVs [8]. Thin airfoils have been shown to perform better than thicker ones at low Reynolds numbers, and so we chose the minimum thickness $(6 \%)$ that was compatible with the available manufacturing process. Profiles with and without camber (NACA4406 and NACA0006 respectively) have been investigated, but in this paper data are presented for the NACA4406 blades only.

Figure 2 shows the predicted variations in turbine output power with shaft speed, and power coefficient (Cp $=$ turbine shaft power / available power in flow) with tip speed ratio $(\mathrm{TSR}=$ blade tip speed / free stream flow speed), for families of optimised 6- and 12-bladed rotors, 
assuming a $5 \mathrm{~ms}^{-1}$ free-stream flow speed. In these plots each data point represents a different turbine design (i.e. a different set of blade twist angles) that is optimised for the given tip speed ratio. A NACA4406 airfoil with $3 \mathrm{~mm}$ chord and $9.7 \mathrm{~mm}$ span is assumed throughout.
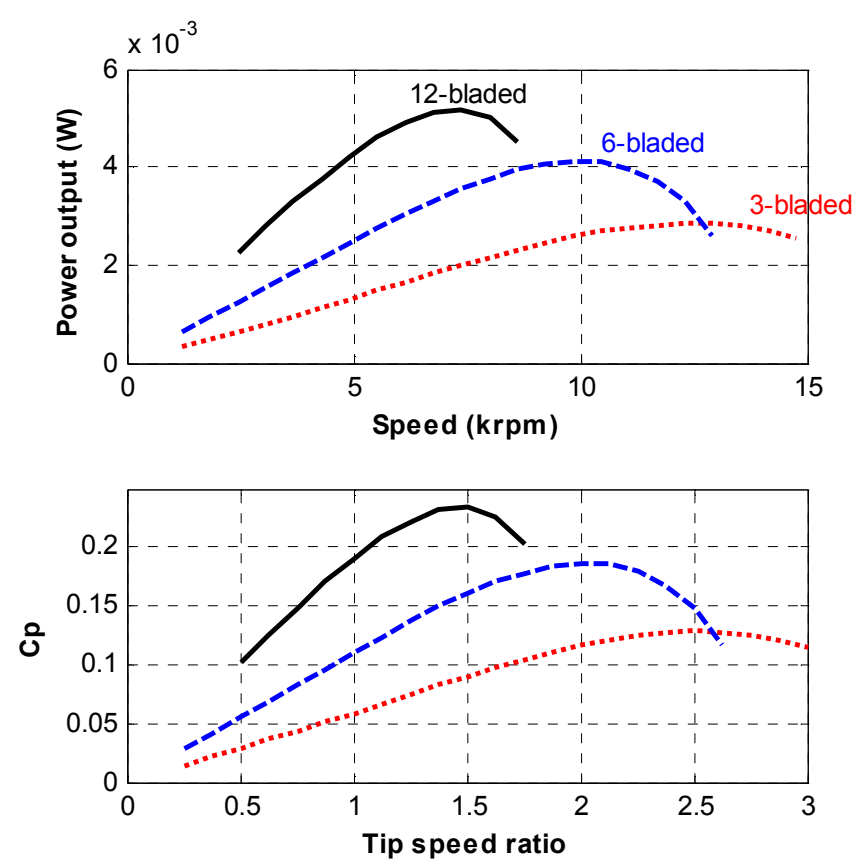

Figure 2: Variations of output power with shaft speed and Cp with TSR for families of optimized 6- and 12-blade rotors, as predicted by BEM model.

It can be seen that lower tip speed ratios and higher blade counts tend to produce higher output power, as predicted by classical wind mill theory when taking drag into account [2]. For example, the maximum possible output power with 6 blades is $4.1 \mathrm{~mW}$ at $10,000 \mathrm{rpm}$ (corresponding to a $\mathrm{Cp}$ of $19 \%$ at TSR $=2$ ), while with 12 blades the maximum possible output power is $5.2 \mathrm{~mW}$ at $7,400 \mathrm{rpm}(\mathrm{Cp}$ of $23 \%$ at TSR $=1.5)$. Blade counts greater than 12 were not possible with the chosen geometry and blade chord. Although the code accounts for blade drag, in practice the shaft power will also be reduced by bearing losses and viscous losses at the hub and shroud (where the generator is situated). Also, no attempt has been made to model the performance implications of swirl in the wake behind the turbine, or of the effect of the shroud around the rotor.

Two particular blade designs were selected for manufacture, corresponding to the maximum power points with 3 and 12 blades. For each design, the radial variation in blade twist angle derived by the BEM analysis was approximated by a linear function as this was all that could be achieved by the manufacturing process.

\section{DEVICE CONSTRUCTION}

A combination of rapid prototyping (RP), traditional machining, and flexible printed circuit technology has been used to realize the prototype devices. Referring to Figure 1, the turbine rotor comprises a central hub, an annular rim, and a variable number of blades, all formed by rapid prototyping. The blades are made by high a resolution (ca $2 \mu \mathrm{m}$ ) process to ensure accurate reproduction of the desired profiles, while a more standard process (ca $50 \mu \mathrm{m}$ resolution) is used for the hub and rim. A $20-\mu \mathrm{m}$ thick electroplated nickel coating is applied to the blades to stiffen them prior to rotor assembly. Figure 3 shows a scanning electron microscope image of a blade immediately after nickel coating. The blades are glued to the hub and rim with the aid of an assembly jig which ensures the rotor is well balanced.

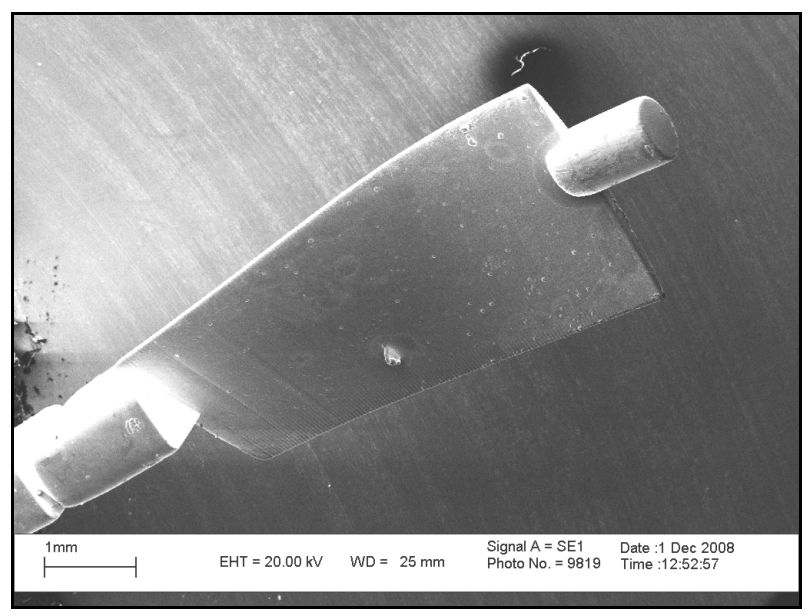

Figure 3: SEM image showing rapid-prototyped turbine blade after nickel coating.

The rotor is mounted in a machined stainless steel casing, supported by a pivot and bearings. Bearing friction and lifetime are key issues for small rotating machines, and starting friction is also critical for energy scavenging turbines because it sets the threshold flow speed for operation. We are currently working with jewel bearings which are known to offer very low starting friction but are as yet unproven in terms of lifetime at high speed.

The generator is a 3-phase, 32-pole AFPM machine, comprising a fixed annular stator coil sandwiched between two permanent magnet rings that sit either side of the rotor rim. The stator coil is implemented as a 4-layer flexible printed circuit with a minimum copper track width of 80 $\mu \mathrm{m}$, a minimum gap between tracks of $50 \mu \mathrm{m}$, and a nominal track height of $20 \mu \mathrm{m}$. Connections to the three generator phases are made via a single lead-out strip which is terminated to suit a standard $0.5 \mathrm{~mm}$-pitch FCC connector. Each magnet ring consists of an aluminium annulus with 32 neodymium-boron-iron $(\mathrm{NdFeB})$ magnets, each $2 \mathrm{~mm}$-dia. $\mathrm{x} 1 \mathrm{~mm}$-long, inserted into it.

Figure 4 shows a photograph of an assembled turbine with a 12-blade rotor fitted. The lead-out strip can be seen at the top. Figure 5 shows the measured open-circuit generator output for this device at $3750 \mathrm{rpm}$ rotation speed. 


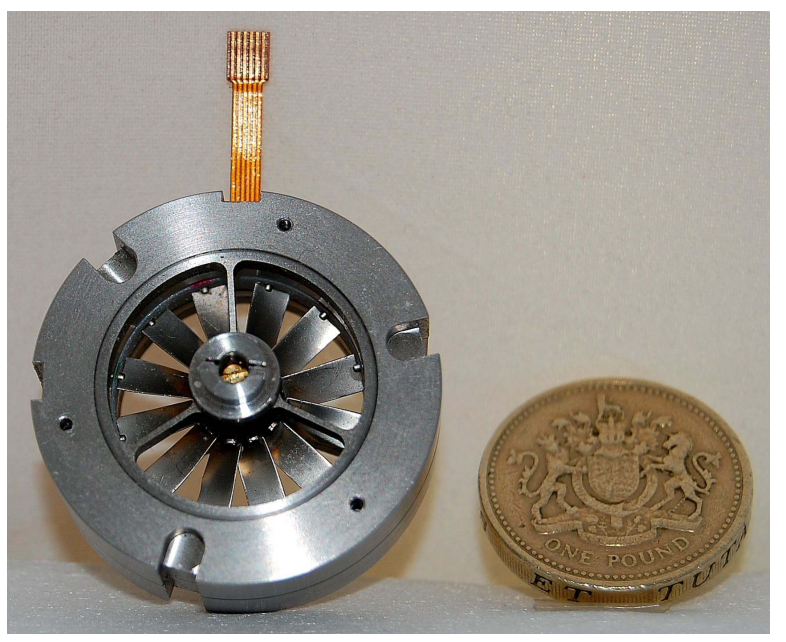

Figure 4: Assembled turbine with 12-blade rotor next to $£ 1$ coin for scale.

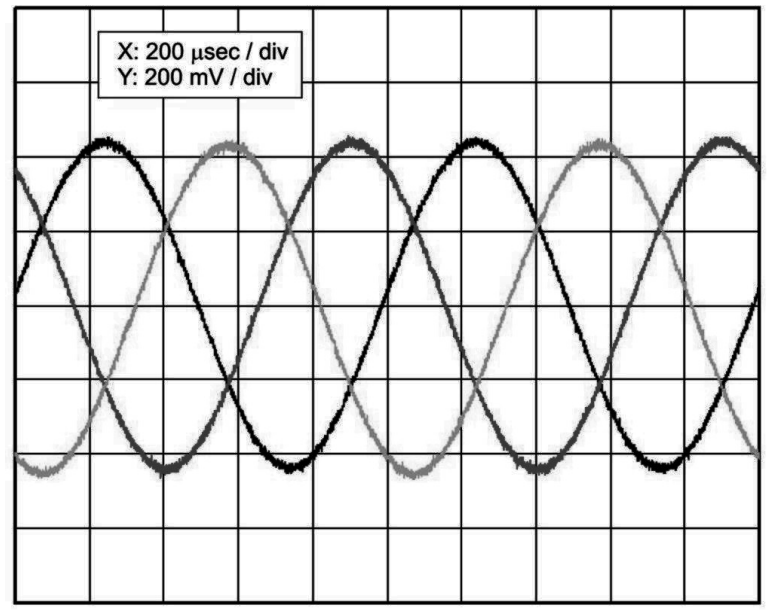

Figure 5: Measured open-circuit 3-phase output from generator when turbine is driven at $3750 \mathrm{rpm}$.

\section{MEASURED PERFORMANCE}

Preliminary performance curves have been obtained for 6-blade and 12-blade turbines using an 18" x 18" wind tunnel (see Figure 6). In both cases the rotors were assembled using blades originally designed for a 3-blade rotor, because the other blade designs have not yet been fabricated. Figure 7 shows the test circuit used, which allows the load imposed by the generator on the turbine to be controlled from a computer, via the voltage $k$. With $k<$ 0 , the same circuit can be used to drive the generator as a synchronous motor.

Figure 8 shows the results for a 12-blade device at several wind tunnel speeds. Both the total shaft power delivered by the turbine, before resistive losses in the generator (but after other generator-related losses), and the power extracted at the generator output are shown. At 10 $\mathrm{ms}^{-1}$ flow the maximum shaft power is $6.3 \mathrm{~mW}$, which is about $5.6 \%$ of the power that would be delivered by a 2 $\mathrm{cm}$-dia. device operating at the Betz limit, and corresponds to a $\mathrm{Cp}$ value of around $3.3 \%$.

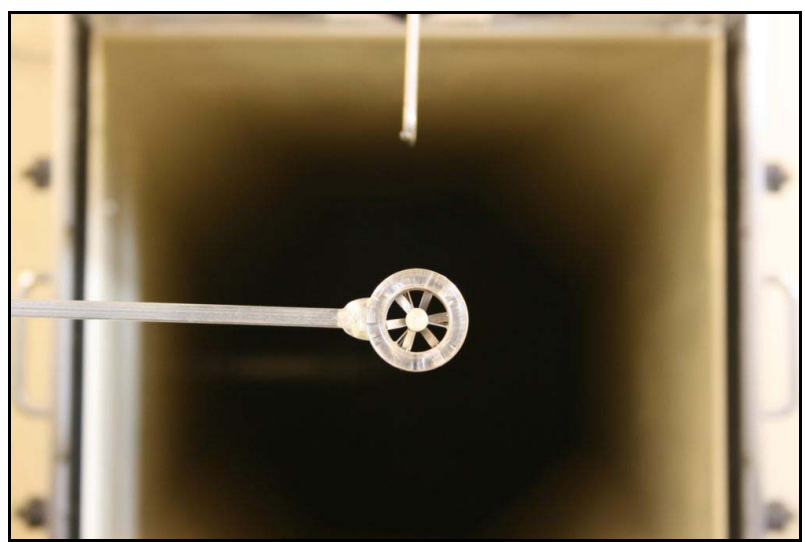

Figure 6: 6-blade turbine mounted in wind tunnel. Pitot tube for tunnel speed measurement can be seen at top of image.

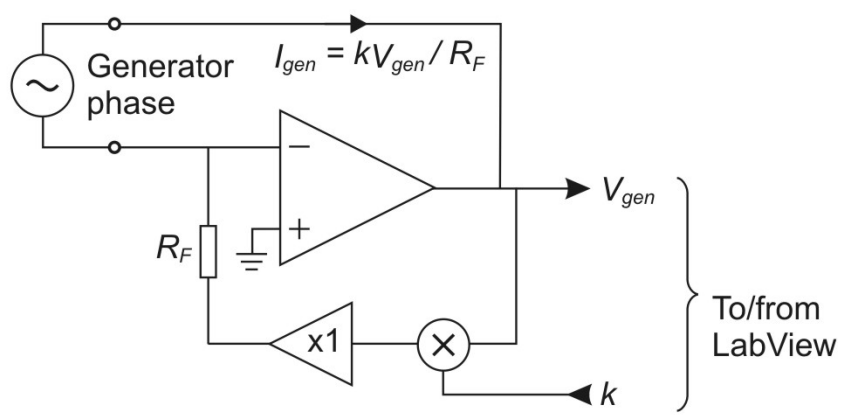

Figure 7: Test circuit used for wind tunnel tests.

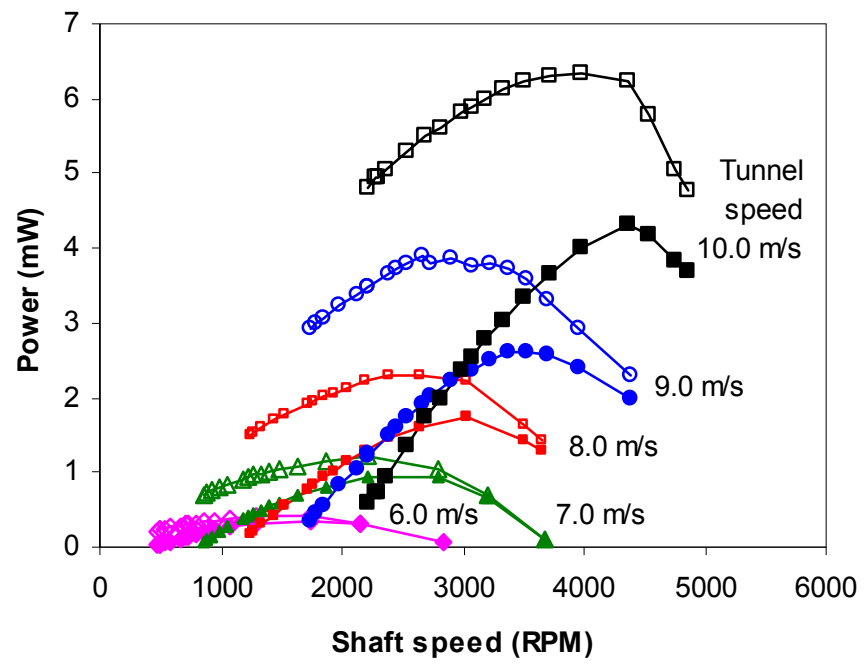

Figure 8: Measured performance curves for 12-blade turbine at different wind tunnel flow speeds. Open plot symbols are turbine shaft power; filled symbols are generator output power.

Figure 9 shows the variation of peak turbine shaft power and generator output power as a function of tunnel speed. Data is shown for tunnel speeds down to $4.8 \mathrm{~ms}^{-1}$, where the maximum generator output power was around $25 \mu \mathrm{W}$. The drop-out tunnel speed, below which the turbine could not operate even with zero load, was about $4.5 \mathrm{~ms}^{-1}$. 


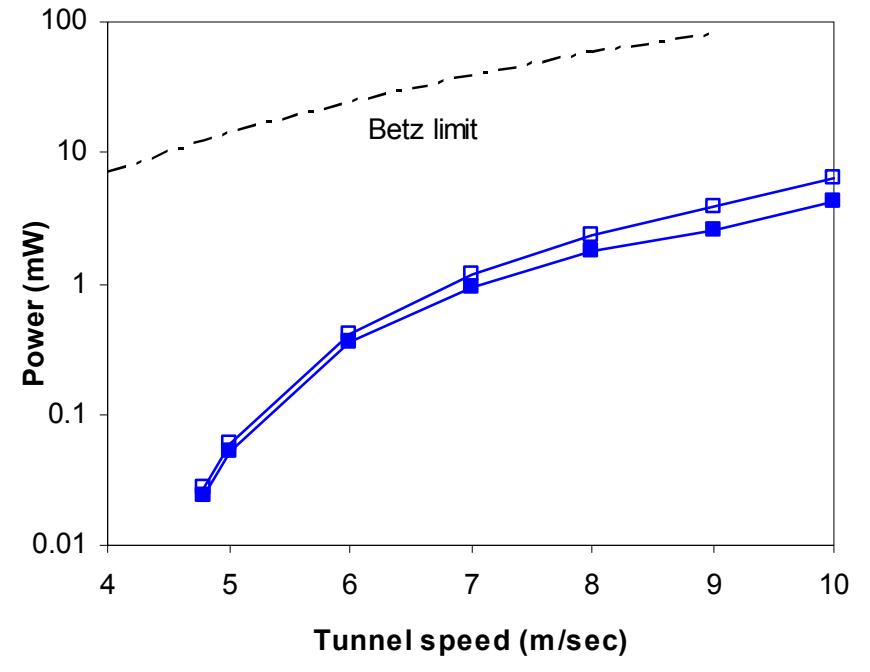

Figure 9: Measured variation of maximum turbine shaft power (open symbols) and maximum generator output power (filled symbols) with tunnel speed, compared to Betz limit.

\section{DISCUSSION}

Comparison between the optimum predicted design performance and the wind tunnel test results shows that the predicted tip speed ratios and power coefficients were not achieved. Instead, the rotors settled to steady state operation at far lower tip speed ratios (TSR $<0.5)$, corresponding to high angles of attack $\left(45^{\circ}<\alpha<55^{\circ}\right)$ on the airfoils and stalled conditions. At these high angles of attack the BEM model as it stands does not produce credible results since lift and drag information for low Reynolds airfoils is not available beyond the stall point (approximately $5^{\circ}<\alpha_{\text {stall }}<9^{\circ}$ ). However, airfoils at high Reynolds numbers do typically exhibit appreciable lift post-stall for $\alpha_{\text {stall }}<\alpha<90^{\circ}$, albeit with increasing drag [9]. It is therefore suggested that sufficient lift is being generated at high angles of attack to cause a stable operating regime at lower tip speed ratios.

The initial results presented here indicate that $\mathrm{cm}$-scale turbines are potentially useful as energy scavengers for wireless sensing. A first prototype has been made that can operate at flow speeds down to $4.5 \mathrm{~ms}^{-1}$ and generate $\mathrm{mW}$ power levels for flow speeds in the range $7-10 \mathrm{~ms}^{-1}$. It is expected that with improved design it will be possible to achieve even lower drop-out speeds.

\section{ACKNOWLEDGEMENTS}

The authors are grateful to Nigel MacCarthy of the Aeronautics Department at Imperial College, London for granting them access to the wind tunnel facility, and to Anthony Oxlade of the same department for his assistance with setting up the wind tunnel tests.

\section{REFERENCES}

[1] C.C. Federspiel, J. Chen, "Air-powered sensor", in Proc. IEEE Sensors 2003, Toronto, Canada, 22-24 Oct 2003, vol. 1, pp. 22-25.

[2] D. Rancourt et al., "Evaluation of centimeter-scale micro windmills: aerodynamics and electromagnetic power generation", in Proc. PowerMEMS 2007, Freiburg, Germany, 28-29 Nov 2007, pp. 93-96.

[3] R. Myers et al., "Small scale windmill", Appl. Phys. Lett., vol. 90, paper 054106, 2007.

[4] S.-H. Kim et al., "An electromagnetic energy scavenger from direct airflow", in Proc. PowerMEMS 2008, Sendai, Japan, 9-12 Nov 2008, pp. 133-136.

[5] A.S. Holmes et al., "Axial-flow microturbine with electromagnetic generator: design, CFD simulation and prototype demonstration", in Proc. MEMS 2004, Maastricht, The Netherlands, 25-29 Jan 2004, pp. 568571.

[6] P. Lissaman, "Low-Reynolds-Number Airfoils", Annual Review of Fluid Mechanics, 1983. vol. 15, no. 1, pp. 223-239.

[7] S. Dixon, Fluid Mechanics and Thermodynamics of Turbomachinery, $5^{\text {th }}$ ed., Elsevier, Amsterdam, 2005.

[8] P. Kunz, "Aerodynamics and design for ultra-low Reynolds number flight", $\mathrm{PhD}$ thesis, Dept. of Aeronautics and Astronautics, Stanford University, 2003.

[9] F.J. Simoes, A steady inviscid flow model for horizontal axis wind turbine rotors under high loading, University of London, 1991.

\section{CONTACT}

* A.S. Holmes, email: a.holmes@ imperial.ac.uk 